\title{
Menstrual characteristics, disorders and associated risk factors among female international students in Zhejiang Province, China: a cross-sectional survey
}

\author{
Emmanuel Ansong ${ }^{1}$, Samuel Kofi Arhin ${ }^{2}$, Yaoyao Cai ${ }^{1}$, Xinxin $\mathrm{Xu}^{1}$ and Xueqing $\mathrm{Wu}^{1 *}$ (D)
}

\begin{abstract}
Background: Until now, no previous study has addressed the menstrual patterns among female international students in China. In this present study, our objectives are to ascertain the menstrual characteristics and address the menstrual problems together with their associated risk factors among international students in China.

Methods: A cross-sectional survey was carried out with 500 previously piloted self-structured questionnaires which were administered to female international students enrolled in 15 universities in Zhejiang Province, China from May 2-August 31, 2016. Participants were required to provide answers to a semi-structured questionnaire which asked questions about their socio-demographics and their menstrual characteristics while in their home countries. Relevant changes in their menstrual pattern in terms of amount of flow and duration, regularity, length and suggestive symptoms for premenstrual syndrome in the months after coming to reside in China were also inquired. Respondents indicated changes in eating habits and selected stressors relevant to them from a given list. Their stress levels were assessed and further categorized with the help of the Perceived Stress Scale (PSS). Measurements for the main outcomes included the characteristics of menstrual patterns after arrival in China, stress levels, stressors and new lifestyle patterns.
\end{abstract}

Results: Four hundred and nine (81.8\%) out of the 500 questionnaires met the criteria and constituted the population for this study. The respondents' mean age was 21.405 years. Almost half of our respondents (49.1\%) reported varying changes in their menstrual pattern after arrival to China. Although, menstrual regularity, normal menstrual length (21-35 days) and duration of flow (3-7 days) remained fairly normal among most of the respondents, disorders like premenstrual symptoms (PMS) (33.82\%); abnormal amount (17.97\%) and dysmenorrhea (16.38\%) were prevalent. There was a significant association between high stress (PSS $>20$ ) and menstrual change $\mathrm{OR}=1.636,95 \% \mathrm{Cl} 1.051-2.547, p=0.029)$ and dysmenorhea $(p=0.037)$. Common stressors included language barrier 81(25.88\%), food 64(20.45\%), and loneliness 56(17.89\%).

Conclusion: Menstrual disorders are high among international students in China. We established premenstrual symptoms as the most common menstrual disorder. High levels of stress (PSS > 20) emanating from factors including the language barrier, diet and loneliness was significantly related to the disruptions in their menstruation.

Keywords: Menstruation, Menarche, Premenstrual symptoms, Dysmenorrhea, International students

\footnotetext{
* Correspondence: wuxueqing.37@hotmail.com

${ }^{1}$ Department of Obstetrics and Gynaecology, The First Affiliated Hospital of

Wenzhou Medical University, Nanbaixiang, Street, Ouhai District, Wenzhou,

Zhejiang Province 325000, People's Republic of China

Full list of author information is available at the end of the article
}

(c) The Author(s). 2019 Open Access This article is distributed under the terms of the Creative Commons Attribution 4.0 International License (http://creativecommons.org/licenses/by/4.0/), which permits unrestricted use, distribution, and reproduction in any medium, provided you give appropriate credit to the original author(s) and the source, provide a link to the Creative Commons license, and indicate if changes were made. The Creative Commons Public Domain Dedication waiver (http://creativecommons.org/publicdomain/zero/1.0/) applies to the data made available in this article, unless otherwise stated. 


\section{Background}

China has become one of the popular study hubs for international students as a result of the recent call for the internationalization and globalization of our world [1]. In 2015 alone, China's Ministry of Education reported a total of 397,635 overseas students enrolled in various institutions. This quotation was almost $6 \%$ higher than that of 2014 , which recorded a total of 377,054 students. The top three famous study destinations for these inbound students were Beijing, Shanghai and Zhejiang [2]. Although the statistics do not specifically detail the number of female students, we believe they constitute a larger portion of this international community.

Menstruation is a normal physiological phenomenon among women of reproductive age. Disorders that are usually linked with menstruation affect women from all parts of the world and it's increasingly becoming one of the major reasons for gynecological visits. Menstrual irregularity is associated with prolonged menstrual bleeding and usually occurs right after the age of menarche as a result of annovulatory cycles. Instability in the endometrial lining that arises as a result of the uncontrolled production of unopposed estrogen causes the breakdown in vasoconstriction and myocardial contractility [3]. During the ovulatory cycle, the production of the prostaglandins in excess is thought to be the cause of the pain in dysmenorrhea. The presence of the prostaglandins causes the contraction of the myometrium and vasoconstriction locally. Elevated levels of serum vasopressin, nitric oxide and interleukin- 6 have also been reported to be implicated in dysmenorrhea [4-6].

Among the student population, disturbances arising from menstruation could contribute to absenteeism, exemption from physical exercises and social and emotional distress. Among adolescents however, delayed, irregular, painful and heavy menstruation are extremely common and remain the chief reasons for physician visits [7]. Premenstrual syndrome greatly affects the student population and causes a considerable amount of anxiety [8]. Dysmenorrhea and menstrual irregularity are also reportedly prevalent among the student population and these also affect these young women's social life and class attendance $[5,9,10]$. On the whole, students who are victims of menstrual disturbances also experience a tremendous impact on their social and physical health [11]. Apart from the pathological factors that disrupt women's cycles, certain environmental factors and dietary or lifestyle trends have also been reported to influence the menstrual pattern like depression, cigarette smoking, changes in body weight and stress [12-15]. International students are reported to be exposed to a wide range of factors in their new environment and are likely to develop new lifestyle habits to help them cope and adapt to their new environment [16-18].
The paucity of information regarding menstrual patterns and the risk factors for menstrual irregularities among female international students in China make this current study extremely necessary. The main focus of the authors of this study was to identify the common menstrual disorders and the factors in their new environment that predispose them to menstrual disturbances. We hypothesized that menstrual changes among international students could be associated with the stress of having to cope or survive in their completely new environment.

\section{Methods}

This cross-sectional survey was done from May to $\mathrm{Au}$ gust, 2016 among female international students selected from 15 universities located in major cities like Hangzhou, Ningbo and Wenzhou, all of which are in Zhejiang Province, China. Permission to carry on with this study was granted after careful evaluation by the Ethics Committee of The First Affiliated Hospital of Wenzhou Medical University in April 2016 (No.wyyy2016-011). Female students included in this study were enrolled in these selected universities, and had been living in China for a year. They had no prior history of primary amenorrhea, bleeding disorders, or any history of abdominal or pelvic surgery. Also, they were at the time of the study not on any medication that could influence their menstrual patterns. Data collection was done using a pretested, structured and validated self-administered English questionnaire (SAQ) consisting of rating scales and close ended questions. We clarified the aims of the study and students were assured that their participation in the study was absolutely voluntary. Prior to the dissemination of the questionnaires, eligible participants were offered instructions sheets on how to answer the questionnaires and had to finally offer an oral acknowledgement whether or not reading and understanding English language was problematic to them. Our research assistants obtained verbal consent from all participants before they proceeded to complete the questionnaires. Instructions were given to complete the questionnaires without inputting their names and were given confidentiality assurance. The questionnaires inquired facts about their socio-demographics, menstrual pattern characteristics and living conditions. We asked them to characterize their menstrual patterns before they arrived to China and also indicate any observable changes in terms of regularity of menstrual cycle, duration and length, amount of menstrual flow and nature of associated menstrual symptoms after their arrival to China. This was to provide us with the opportunity to properly classify the section of participants with changes in their menstrual pattern and to look for potential risk factors. The criteria that defined menstrual cycle were as 
follows; irregular menstrual cycles: varying cycle length less than 21 or more than 35 days, regular menstrual cycles: cycle length of 21-35 days, hypomenorrhea (menstrual flow less than 2 days), prolonged menstrual flow (menstrual flow of more than 7 days), and amount of blood loss as reflected by the number of sanitary towels or pads changed per day during menstruation categorized as little, moderate and heavy for 4 pads, 5-7 pads and a maximum of 8 pads per day respectively. Included in the questionnaire were list of symptoms indicative of premenstrual symptoms (PMS) and respondents were to select ones applicable to them.

They were also asked to provide answers to questions regarding their living conditions which included specifics like dietary habits, stress and common stressors. We integrated the Perceived Stress Scale (PSS) in the question to enable us evaluate their stress levels. To evaluate their stress levels, we incorporated the Perceived Stress Scale (PSS), which examined their thoughts and feelings during the previous month. The scale is made up of 5-point Likert response format (0-4). The sum of the responses indicates the total score. Overall scores on the PSS-10 can range from zero to forty (0-40). Respondents with PSS value of $\leq 20$ and $>20$ were categorized as low stress and high stress respectively. In addition, variables such as language barrier, academic pressure, money, loneliness, homesickness and food were provided for, which respondents could selectively indicate as stressors. New social habits including smoking, drinking, late sleeping, lack of exercise and lack of socialization were used to investigate new lifestyle patterns.

Where appropriate, data were expressed as numbers in the form of percentages or as mean $\pm \mathrm{SD}$. Data were taken through revision, coded and tabulated using the frequency and percentage to analyze and interpret the results. Logistic regression and odds ratio were done to identify risk factors for menstrual change and to test the significance of the variables, $p<0.05$. All calculations were statistically carried out with the help of Statistical Package for the Social Science (SPSS); SPSS Inc., Chicago, IL, USA) version 20.0 for Microsoft Windows.

\section{Results}

We circulated five hundred (500) questionnaires in total but 40 of them were not returned. Out of the 460 that were returned, 51 were rejected due to lack of information giving a response rate of $81.8 \%$. The remaining four hundred and nine (409) questionnaires met the criteria and were used for the analysis. Two hundred and one $(n=201,49.14 \%)$ respondents reported noticeable menstrual changes after arrival to China and were categorized as the "Change group". Among two hundred and eight $(n=208,50.86 \%)$ participants, menstrual patterns remained unchanged in the months after arrival to China and was referred to as the "No change group".

\section{General characteristics and demographics of participants} The population had a median $( \pm \mathrm{SD})$ of $27.89 \pm 2.77 \mathrm{~kg} /$ $\mathrm{m}^{2}$ for BMI and a mean age of 21.405 years for a range of 17-35 years. Health Science 238 (58.19\%) was the most popular program among the respondents. Only 49 (11.98\%) of the respondents read Business related courses with only $32(7.82 \%)$ studying engineering courses. The larger portion of the respondents 203(49.63\%) were nationals from Africa, with the least 20(4.89\%) from Europe (Table 1).

\section{Menstrual characteristics for the change group}

Two hundred and one 201(49.14\%) respondents reported varying changes in their menstruation (Change group). With a range of 9 to 16 years, majority 173 (86.07\%) of the respondents had menstruated by age 13 with the mean onset of menarche as 11.830 years. Characteristic menstruation comprised: regular menses in $75.62 \%$ (152), $43.78 \%$ (88) for cycle length with a range of 21 to 35 days, $46.26 \%$ (68) for duration of flow with a range of 3-7 days and moderate flow as reflected by the use of 5 -7pads/day was $32.34 \%(n=65)$. Menstrual irregularity was recorded in $49(24.38 \%)$ of the respondents. PMS was the most prevalent 256 (33.82\%) menstrual disorder among our respondents. Most physical premenstrual symptoms were headaches 66(22.07\%), bloating $23(7.69 \%)$, breast tenderness $13(4.35 \%)$ and back pain $12(4.01 \%)$ with irritability $16(5.35 \%)$ scoring the most reported psycho-behavioral premenstrual symp tom. Other reported abnormalities included; abnormal amount 136(17.97\%), dysmenorrhea $124(16.38 \%)$, abnormal length 113(14.93\%) and abnormal duration 79(10.45\%) (Table 2).

\section{Analysis of statistical significance between factors and menstrual changes}

Among our overall population, 248(60.64\%) and $161(39.36 \%)$ were classified as high stress (PSS $>20)$ and low stress (PSS $\leq 20$ ) respectively according to the PSS scale. High stress (PSS $>20$ ) was the significant factor among the population that showed a strong association between the two groups $[p=0.029, \quad \mathrm{OR}=1.636, \mathrm{CI}$ 1.021-2.547]. Alcohol consumption, lack of exercise and lack of socialization showed increased risks for menstrual change with (OR 1.993,CI 0.671-5.921), (OR 1.389 CI $0.891-2.167$ ) and (OR 1.306 CI $0.562-3.038$ ) respectively. Lack of exercise was credited as the prevalent 203 (49.63\%) of new social habits developed after arrival in China. Late sleeping and lack of socialization were the next common habits among the respondents scoring $180(44.01 \%)$ and $29(7.09 \%)$ respectively. Only18 
Table 1 General Characteristics and Demographics of Participants. $(n=409)$

\begin{tabular}{|c|c|c|c|c|c|c|}
\hline \multicolumn{2}{|c|}{ DEMOGRAPHICS } & \multicolumn{4}{|c|}{ STUDENTS POPULATION } & \multirow{3}{*}{$P$ value } \\
\hline & & \multicolumn{2}{|l|}{ CHANGE } & \multicolumn{2}{|c|}{ NO CHANGE } & \\
\hline & & Number & Percentage (\%) & Number & Percentage (\%) & \\
\hline \multirow[t]{4}{*}{ Age } & $17-20$ & 87 & 43.28 & 80 & 38.46 & \\
\hline & $21-25$ & 100 & 49.75 & 120 & 57.69 & 0.239 \\
\hline & $26-30$ & 6 & 2.99 & 2 & 0.96 & \\
\hline & $31-35$ & 8 & 3.98 & 6 & 2.89 & \\
\hline \multirow[t]{4}{*}{ BMl } & Underweight(< 18.5) & 1 & 0.50 & 1 & 0.48 & \\
\hline & Normal weight (18.5-24.9) & 72 & 35.82 & 93 & 44.71 & 0.142 \\
\hline & Overweight (25-29.9) & 77 & 38.31 & 78 & 37.50 & \\
\hline & Obese $(>30)$ & 51 & 25.37 & 36 & 17.31 & \\
\hline \multirow[t]{4}{*}{ Program } & Health Science & 118 & 58.7 & 120 & 57.70 & \\
\hline & Engineering & 10 & 5.0 & 22 & 10.60 & 0.145 \\
\hline & Business & 28 & 13.9 & 21 & 10.10 & \\
\hline & Others & 45 & 22.4 & 45 & 21.60 & \\
\hline \multirow[t]{5}{*}{ Country } & Africa & 110 & 54.72 & 93 & 44.71 & \\
\hline & Asia & 60 & 29.85 & 87 & 41.83 & 0.024 \\
\hline & Europe & 9 & 4.48 & 11 & 5.29 & \\
\hline & Arab & 13 & 6.47 & 15 & 7.21 & \\
\hline & Others & 9 & 4.48 & 2 & 0.96 & \\
\hline
\end{tabular}

(4.4\%) of the respondents had developed the habit of alcohol consumption (Table 3).

\section{Main stressors among the general population}

The commonest stressor among the study population was the language barrier $81(25.88 \%)$ followed by food 64(20.45\%), loneliness 56(17.89\%) and homesickness $40(12.78 \%)$. Finance was considered as a stressor among $35(11.18 \%)$ with only $32(10.22 \%)$ rating their respective academic programs as a form of stressor (Fig.1).

\section{Relationship between high stress level and menstrual disorders}

We attempted to establish the relationship of the various factors with menstrual irregularities and found out high stress was also significantly associated the risk of dysmenorrhea $(p=0.037)$. Although other factors like age, age of menarche, program of study, alcohol consumption, lack of exercise, lack of socialization and BMI did not show strong significant associations they increased the respondents' risk of developing menstrual irregularities (Table 4).

\section{Discussion}

This is the maiden study done to throw more light on the menstrual characteristics, disorders and associated risk factors among female international students in Zhejiang Province, China. This study revealed that international students are exposed to factors in varying degrees that can potentially cause disruptions in their menstrual patterns. These irregularities can have significant effects on these women's life, health and work [15]. In close to $80 \%$ women with normal ovulation, the estimated blood loss on average is about $33.2 \mathrm{ml}(10-84 \mathrm{ml})$, cycle length of $26-35$ days, bleeding follows a 3-6 day period with a range of 212 days with the maximum flow on the second day [11]. The onset of menstruation is marked by menarche which is a very important indicator of sexual maturity in females. The mean age for the onset of menarche is reported differently worldwide and Africans are reported to have the earliest age of menarche probably attributed to their high body mass index $[19,20]$. The age of menarche is also crucial since women who experience menarche much later have a higher risk for menstrual irregularities [21].

Unusually infrequent (oligomenorhea), unusually light (hypomenorrhea), heavy flow (menorrhagia), metrorrhagia, unusually painful (dysmenorrhea), premenstrual syndrome (PMS), absent or delayed menstruation (amenorr hea) and unusually frequent (polymenorrhea) are among the types of menstrual disorders women suffer and the number one reason for gynecologic visits [22, 23]. The reasons for irregularities in menstruation vary as women age and can occur due to a plethora of conditions ranging from hormonal imbalances, pregnancy, malignancies, infections, diseases, trauma to the use of certain medications [24-29]. Environmental factors and new 
Table 2 Menstrual Characteristics for the Change Group ( $n=201)$.

\begin{tabular}{|c|c|c|c|}
\hline Menstrual Characteristics & Parameters & Number & Percentage (\%) \\
\hline \multirow[t]{4}{*}{ Age of menarche } & 9-10 years & 33 & 16.42 \\
\hline & $11-13$ years & 140 & 69.65 \\
\hline & $14-16$ years & 28 & 13.93 \\
\hline & Total: & 201 & 100.00 \\
\hline \multirow[t]{3}{*}{ Menstrual regularity } & Regular & 152 & 75.62 \\
\hline & Irregular & 49 & 24.38 \\
\hline & Total: & 201 & 100.00 \\
\hline \multirow[t]{4}{*}{ Menstrual Length } & $<21$ days & 52 & 25.87 \\
\hline & $21-35$ days & 88 & 43.78 \\
\hline & $>35$ days & 61 & 30.35 \\
\hline & Total: & 201 & 100.00 \\
\hline \multirow[t]{4}{*}{ Duration of flow } & $<3$ days & 36 & 24.49 \\
\hline & 3-7 days & 68 & 46.26 \\
\hline & $>8$ days & 43 & 29.25 \\
\hline & Total: & 147 & 100.00 \\
\hline \multirow[t]{4}{*}{ Amount of flow } & Little (4pads/day) & 60 & 29.85 \\
\hline & Moderate (5-7 pads/day) & 65 & 32.34 \\
\hline & Heavy (max 8pads/days) & 76 & 37.81 \\
\hline & Total: & 201 & 100.00 \\
\hline Dysmenorrhea (Abdominal cramps) & & 124 & 100.00 \\
\hline \multirow[t]{12}{*}{ Premenstrual Symptoms(PMS) } & Bloating & 23 & 7.69 \\
\hline & Back Pain & 12 & 4.01 \\
\hline & Headache & 66 & 22.07 \\
\hline & Nausea \& Vomiting & 2 & 0.67 \\
\hline & Breast tenderness & 13 & 4.35 \\
\hline & Constipation & 0 & 0 \\
\hline & Irritability & 16 & 5.35 \\
\hline & Fever & 0 & 0 \\
\hline & Diarrhea & 0 & 0 \\
\hline & Others & 1 & 0.33 \\
\hline & None & 39 & 13.04 \\
\hline & Total: & 295 & 100.00 \\
\hline
\end{tabular}

lifestyle trends like caffeine consumption, physical activity, stress, smoking, age, weight gain and diet have also been closely correlated with menstrual disorders [30-35].

Premenstrual menstrual symptoms (PMS) was ascribed the main menstrual disorder (33.82\%) among the group with change in their menstrual pattern. PMS is characterized by a multifarious pattern change in mood, behavior and physical symptoms invariably experienced during the premenstrual phase and resolve quickly before the onset of menstruation. It is reported that approximately $5 \%$ of women experience severe forms of PMS that distorts both their personal and social interactions [8]. Unlike in our study, which indicated headaches as the commonest premenstrual symptom, literature reports irritability and anger as the commonest and severe forms of PMS with an onset than earlier to other symptoms [36].

Abnormal amount 136 (17.97\%) was reported as the second menstrual disorder among our respondents with menstrual changes. Personalized estimation of menstrual flow volume and hygiene coupled with different sanitary products on the market make the estimation of the accurate menstrual blood flow extre mely difficult. Various quantification methods for menstrual blood loss estimation have been reported 
Table 3 Analysis of statistical significance between factors and menstrual changes $(n=409)$

\begin{tabular}{|c|c|c|c|c|c|c|c|c|}
\hline \multirow[t]{3}{*}{ Indicator } & \multicolumn{4}{|c|}{ Menstrual Pattern } & \multirow{3}{*}{$P$-Value } & \multirow{3}{*}{ Odds Ratio } & \multirow{2}{*}{\multicolumn{2}{|c|}{ OR95\%Cl }} \\
\hline & \multicolumn{2}{|c|}{ No Change } & \multicolumn{2}{|l|}{ Change } & & & & \\
\hline & Number & $\%$ & Number & $\%$ & & & LOWER & UPPER \\
\hline \multicolumn{9}{|l|}{ Age } \\
\hline $17-20$ & 80 & 47.90 & 87 & 52.10 & 0.8676 & 1.1040 & 0.344752 & 3.535526 \\
\hline $21-25$ & 120 & 54.55 & 100 & 45.45 & 0.8548 & 0.8970 & 0.280026 & 2.873634 \\
\hline $26-30$ & 2 & 25.00 & 6 & 75.00 & 0.3408 & 2.6660 & 0.354385 & 20.05635 \\
\hline $31-35$ & 6 & 42.86 & 8 & 57.14 & - & - & - & - \\
\hline \multicolumn{9}{|l|}{$\mathrm{AOM}$} \\
\hline $9-10$ years & 27 & 45.00 & 33 & 55.00 & - & - & - & - \\
\hline 11-13 years & 155 & 52.54 & 140 & 47.46 & 0.8452 & 0.9406 & 0.508649 & 1.739472 \\
\hline $14-16$ years & 26 & 48.15 & 28 & 51.85 & 0.4028 & 1.4368 & 0.614638 & 3.358937 \\
\hline \multicolumn{9}{|l|}{ BMI } \\
\hline Normal & 94 & 56.97 & 71 & 43.03 & 0.9886 & $4.2651 \mathrm{E}-9$ & 0.0 EO & \\
\hline Overweight & 78 & 50.32 & 77 & 49.68 & 0.9999 & 10.4435 & 0.0EO & . \\
\hline Obese & 36 & 41.38 & 51 & 58.62 & 0.9996 & 7.7275E-9 & 0.0EO & . \\
\hline \multicolumn{9}{|l|}{ Country } \\
\hline Africa & 93 & 45.81 & 110 & 54.19 & 0.1248 & 0.27794 & 0.054173 & 1.426003 \\
\hline Arab & 15 & 53.57 & 13 & 46.43 & 0.1708 & 0.28153 & 0.045896 & 1.726932 \\
\hline Asia & 87 & 59.18 & 60 & 40.82 & 0.0386 & 0.17774 & 0.034559 & 0.914166 \\
\hline Europe & 11 & 55.00 & 9 & 45.00 & 0.0470 & 0.15242 & 0.023799 & 0.976166 \\
\hline Others & 2 & 18.18 & 9 & 81.82 & - & - & - & - \\
\hline \multicolumn{9}{|l|}{ Program } \\
\hline Health & 120 & 50.42 & 118 & 49.58 & 0.4653 & 0.773 & 0.387 & 1.543 \\
\hline Business & 30 & 42.86 & 40 & 57.14 & 0.898 & 1.053 & 0.478 & 2.317 \\
\hline Engineering & 32 & 64.00 & 18 & 36.00 & 0.028 & 0.367 & 0.150 & 0.895 \\
\hline Others & 26 & 50.98 & 25 & 49.02 & - & - & - & - \\
\hline \multicolumn{9}{|l|}{ Stress } \\
\hline$\leq 20$ & 96 & 59.63 & 65 & 40.37 & - & - & - & - \\
\hline$>20$ & 112 & 45.16 & 136 & 54.84 & 0.029 & 1.636 & 1.051 & 2.547 \\
\hline \multicolumn{9}{|l|}{ Food } \\
\hline Chinese & 37 & 48.68 & 39 & 51.32 & 0.693 & 0.897 & 0.523 & 1.539 \\
\hline Western & 154 & 50.00 & 154 & 50.00 & - & - & - & - \\
\hline CAW & 17 & 68.00 & 8 & 32.00 & 0.158 & 0.523 & 0.213 & 1.284 \\
\hline \multicolumn{9}{|l|}{ Social } \\
\hline Drinking & 7 & 38.89 & 11 & 61.11 & 0.215 & 1.993 & 0.671 & 5.921 \\
\hline \multicolumn{9}{|l|}{ Habits } \\
\hline LS & 101 & 56.11 & 79 & 43.89 & 0.254 & 0.766 & 0.485 & 1.211 \\
\hline LOE & 94 & 46.77 & 109 & 53.23 & 0.147 & 1.389 & 0.891 & 2.167 \\
\hline LOS & 13 & 44.83 & 16 & 55.17 & 0.535 & 1.306 & 0.562 & 3.038 \\
\hline
\end{tabular}

to provide unreliable and conflicting outcomes [37]. In our study, we employed the use of the traditional method, whereby women self-estimated their menstrual loss by counting the number of sanitary products used per day. This method is convenient and has been reported to correlate with the correct amount of menstrual blood loss [38]. Nevertheless, future studies could preferably make use of a more reliable approach to quantify menstrual blood loss since the amount of menstrual blood loss is a useful tool in the 


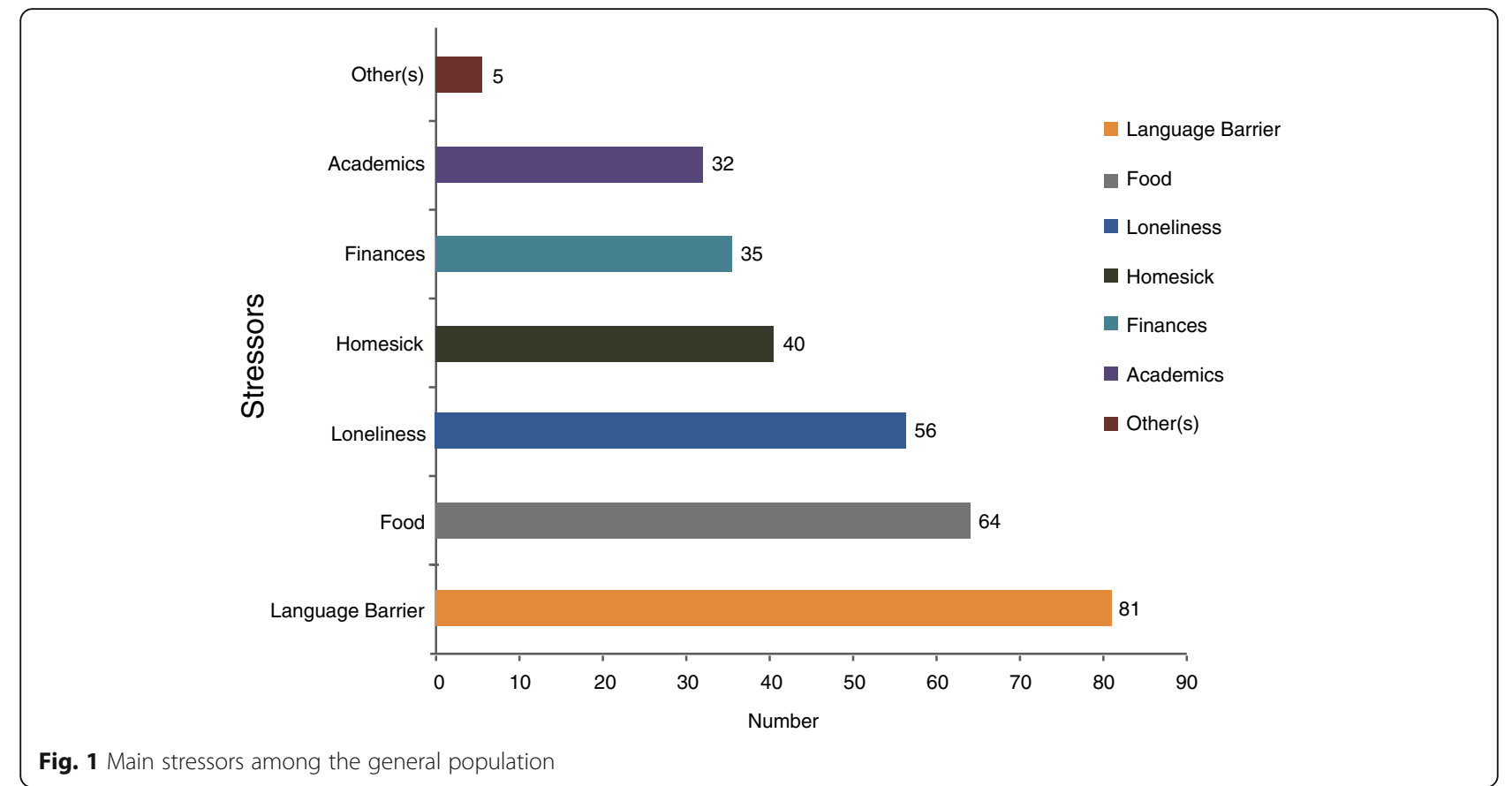

assessment of an individual's productivity, general well-being and iron status [39, 40].

Dysmenorrhea was the third predominant menstrual disorder (16.38\%) among our respondents. Although it is a common gynecological complaint among women in developing countries, it's characterized by varied prevalence rate in literature. In one large study conducted among Australian teenagers for example, the prevalence was $93 \%$ and in another study among 664 Egyptian teenagers, the prevalence was reported as $80 \%[41,42]$. This difference has been linked to individual differences in pain threshold, cultural differences in the perception of pain and the absence of a standardized universal method to assess and grade dysmenorrhea [43].

One of the widely used instruments employed in the assessment of psychological stress among individuals with respect to varying situations over the past months is the perceived stress scale (PSS) [44]. With the help of the PSS, our general population was categorized as low stress $(\mathrm{PSS} \leq 20)$ and high stress (PSS $>20)$ and we discovered more than half $(60.64 \%)$ of the study population were high stress. This buttresses the point that international students

Table 4 Relationship between high stress level and menstrual disorders $(n=201)$

\begin{tabular}{|c|c|c|c|c|c|c|c|c|}
\hline \multirow{3}{*}{$\begin{array}{l}\text { Menstrual } \\
\text { Disorders }\end{array}$} & \multicolumn{4}{|l|}{ Grade } & \multirow[t]{3}{*}{$P$-Value } & \multirow{3}{*}{$\begin{array}{l}\text { Odds } \\
\text { Ratio }\end{array}$} & \multirow{2}{*}{\multicolumn{2}{|c|}{ OR95\%Cl }} \\
\hline & \multicolumn{2}{|c|}{ High stress } & \multicolumn{2}{|c|}{ Low stress } & & & & \\
\hline & Number & $\%$ & Number & $\%$ & & & LOWER & UPPER \\
\hline Irregular & 30 & 100.0 & 19 & 100.0 & .892 & .946 & .425 & 2.105 \\
\hline \multicolumn{9}{|l|}{ Menstrual Length } \\
\hline$<21$ days & 35 & 44.30 & 17 & 50 & .605 & 1.276 & .506 & 3.218 \\
\hline$>35$ days & 44 & 55.70 & 17 & 50 & .453 & .713 & .295 & 1.724 \\
\hline \multicolumn{9}{|l|}{ Duration of flow } \\
\hline$<3$ days & 26 & 48.15 & 10 & 40 & .118 & .440 & .157 & 1.233 \\
\hline$>8$ days & 28 & 51.85 & 15 & 60 & .871 & .931 & .390 & 2.220 \\
\hline \multicolumn{9}{|l|}{ Amount of flow } \\
\hline Little & 38 & 40.43 & 22 & 52.38 & .156 & 1.976 & .770 & 5.070 \\
\hline Heavy & 56 & 59.57 & 20 & 47.62 & .986 & .992 & .411 & 2.393 \\
\hline Dysmenorrhea & 90 & 100.0 & 37 & 100.0 & .037 & .172 & .033 & .896 \\
\hline PMS & 136 & 100.0 & 65 & 100.0 & .069 & .940 & .880 & 1.005 \\
\hline
\end{tabular}


experience a great deal of stress that emanates from difficulties with adjustment, support, perceived discrimination, homesickness, insecurity, anxiety, depression, language and academics [16-18].

The female reproductive system is very sensitive to physical and physiological stress. Although small doses of stress can motivate individuals to respond to changes, face challenges and complete tasks, high stress can have detrimental physical and psychological health effects. When the corticotrophin-releasing hormone system is activated as a physiological response to stress, menstrual function can be consequently disrupted [45]. The correlation of menstrual irregularities and high stress in our study is in line with the various publications that have registered menstrual changes in universities students studying demanding courses or individuals with competitive life style including severe exercises [35, 46, 47]. High stress (PSS $>20$ ) was also found to be significantly correlated with dysmenorrhea $(p=0.037)$ in our study. Stress impairs the development of the follicle by inhibiting the release of follicle-stimulating hormone and luteinizing hormone. This may in turn alter progesterone synthesis and release which may affect the action of prostaglandin. Other stress related hormones like adrenaline and cortisol also can influence prostaglandin synthesis and/or binding in the myometrium and may explain the role of stress in dysmenorrhea. A positive association has also been reported between perceived stress and the risk of dysmenorrhea in both longitudinal and cross-sectional studies [23, 48-50]. The most prevalent stressor among our respondents was language barrier $81(25.88 \%)$ which may be attributed to the study of Chinese language as part of their academic curriculum or their limited scope of socialization due to having very few English speaking colleagues around them. The issue of language barrier goes beyond just being a stressor, as it can hinder physician consultation, hamper doctor-patients communication or result in poorer compliance and less patient satisfaction [16]. Other common stressors among our study population included food 64 (20.45\%), loneliness 56 (17.89\%), homesickness 40 (12.78\%) and academic issues 32(10.22\%).

In our attempt to investigate our respondents' new lifestyle trends, lack of exercise was found to be the prevalent new social habit developed months after living in China. A significant association between lack of exercise and premenstrual symptoms has been reported in several studies. In one publication, aerobic exercises was evidenced as one of the options to help alleviate the symptoms of premenstrual symptoms [51]. Late sleeping was the second reported habit after arrival to China. This finding is not surprising, since the issue of sleep problems is significantly escalated during university, and among international students, due to problems with adjusting to new environment and dormitory settings [52]. The few reports of lack of socialization as a new social habit among our students could be attributed to the issue of language barrier which limits the scope of socialization and interpersonal interactions.

Our present study is limited in some areas that we will like to address. Firstly, the present study involved students who were enrolled in universities studying very demanding courses, which could obviously be viewed as potential stressors. Further comparative studies with foreigners who are not students or domestic students from other provinces are needed to generalize the results. Causality inference of the factors identified as being correlated with menstrual change is highly limited by virtue of our choice of study design. Prospective follow up studies are therefore needed to look for causality. Another limitation of our study lies in the type of instruments we utilized. Although, the application of the 20 or higher cut-off point to categorize women with high stress was recommended by Cohen et al. [44], recall bias and differences in individualized interpretation could be a possible limitation since stress levels were assessed by questions from the previous months. The reader should also remember that participants estimated their menstrual amount and duration by calculating the quantities of sanitary pads used or by the number of days of menstruation and blood loss. This approach is likely to also suffer varying degrees of individual variations. Future studies could employ the use of a more objective quantification like the menstrual pictogram [53].

\section{Conclusion}

Menstrual disorders are prevalent among the international student community as a result of a wide range of factors that contribute to the irregularity of menstrual patterns. In the present study, the most common disorder these students experienced was premenstrual symptoms, followed by abnormal amount and dysmenorrhea. The most predominant premenstrual symptom was headaches, followed by bloating and irritability. The top three main forms of stressors among the general student population were language barrier, food and loneliness. These stressors accounted for a high level of stress (PSS > 20) among more than half of the students who have witnessed changes in their menstrual pattern and this high stress was significantly correlated with dysmenorrhea. Although, the formation of new social habits did not show strong association with menstrual disorders among the students body, it was striking to note that majority of these international students do not engage in exercises and sleep rather late. With the large scale movement of international students into Chinese Universities and Colleges, we believe additional studies with larger population size across major universities in China 
are needed to broadly assess this problem to help illuminate its prevalence. It is important that prospective studies which are done can include factors that can influence stress, such as cultural and religious background, social support and personality type, so that respective universities can develop and strategize appropriate interventions to help eradicate or minimize the effect of these potential factors that predispose these individuals to menstrual irregularities.

\section{Abbreviations}

BMI: Body mass index; CAW: Chinese and Western; LOE: Lack of exercise: LOS: Lack of socialization; LS: Late sleeping; PMS: Premenstrual symptoms; PSS: Perceived Stress Scale

\section{Acknowledgements}

The authors thank greatly the teachers in the school of Public Health in Wenzhou Medical University. Also, the international offices of the universities the study was conducted for their help and understanding.

Tabulated categorization of the entire study population into two groups based on their age, BMI, program of study and country of origin expressed as percentages.

This table shows the detailed menstrual characteristics among the group with menstrual changes. We investigated the frequency of each variable and expressed each as a percentage.

We used the regression analysis to test for the predictive power, odds ratios and confidence intervals of the various identified risk factors we identified among the study population.

Two main groups as high stress and low stress,we used simple linear regression to calculate the predictive values, odds ratios and confidence intervals to help understand the relation of stress to the menstrual disorders. We calculated the numbers for the various stressors identified in our study population and plotted a graph with respect to their various numbers to express the common stressors reported among them.

\section{Funding}

This work was supported by: The Public Welfare Scientific and Technology Project of Wenzhou City (No.Y20140743), The Science and Technology Project of Zhejiang Province (No.2016C37132) and The Natural Science Foundation of Zhejiang Province(No.LY17H040009).

\section{Availability of data and materials}

The data supporting these findings will not be made available publically due to concerns about protecting participants' identity and respecting their rights to privacy. Although participants agreed to take part in the study we did not get their permission to publish the dataset.

\section{Authors' contributions}

EA conceived, designed the study and drafted the manuscript, SKA, YC and XX helped data collection, analyzed the data and help draft the manuscript. XW revised the manuscript, providing intellectual content. All authors commented on and approved the final manuscript.

\section{Ethics approval and consent to participate}

This study was approved by the ethic committee of First Affiliated Hospital of Wenzhou Medical University (No.wyyy2016-011). Our research assistants explained the written consent forms with participants, after which they were given the chance to independently read the consent forms and ask relevant questions prior to signing the consent form.

\section{Consent for publication}

Not applicable as this manuscript does not include details, images, or videos relating to individual participants.

\section{Competing interests}

Authors declare that they have no competing interests.

\section{Publisher's Note}

Springer Nature remains neutral with regard to jurisdictional claims in published maps and institutional affiliations.

\section{Author details}

'Department of Obstetrics and Gynaecology, The First Affiliated Hospital of Wenzhou Medical University, Nanbaixiang, Street, Ouhai District, Wenzhou, Zhejiang Province 325000, People's Republic of China. ${ }^{2}$ Department of Reproductive Medicine, The Second Affiliated Hospital of Wenzhou Medical University, Xueyuan Western Road, Lucheng District, Wenzhou, Zhejiang Province 325027, People's Republic of China.

Received: 27 June 2017 Accepted: 30 January 2019

Published online: 18 February 2019

\section{References}

1. Rezaei H, Yousefi A, Larijani B, Dehnavieh R, Rezaei N, Adibi P. Internationalization or globalization of higher education. J Educ Health Promot. 2018;7:8.

2. China releases report on foreign students for 2015 http://en.moe.gov.cn/ News/Top_News/201604/t20160420_239196.html. Accessed 6 Oct 2016.

3. Bayer SR, DeCherney AH. Clinical manifestations and treatment of dysfunctional uterine bleeding. JAMA. 1993;269(14):1823-8.

4. Sun MF, Huang HC, Lin SC, Chang LP, Liu CF. Evaluation of nitric oxide and homocysteine levels in primary dysmenorrheal women in Taiwan. Life Sci. 2005;76(17):2005-9.

5. Yeh ML, Chen HH, So EC, Liu CF. A study of serum malondialdehyde and interleukin-6 levels in young women with dysmenorrhea in Taiwan. Life Sci. 2004;75(6):669-73.

6. Durain D. Primary dysmenorrhea: assessment and management update. J Midwifery Womens Health. 2004;49(6):520-8.

7. Chan SS, Yiu KW, Yuen PM, Sahota DS, Chung TK. Menstrual problems and health-seeking behaviour in Hong Kong Chinese girls. Hong Kong Med J. 2009;15(1):18-23.

8. Dimmock PW, Wyatt KM, Jones PW, O'Brien PM. Efficacy of selective serotonin-reuptake inhibitors in premenstrual syndrome: a systematic review. Lancet. 2000;356(9236):1131-6.

9. Bitzer J, Tschudin S, Stadlmayr W. Menstruation and its impact on women's health. Zentralbl Gynakol. 2005;127(5):282-7.

10. Houston AM, Abraham A, Huang Z, D'Angelo LJ. Knowledge, attitudes, and consequences of menstrual health in urban adolescent females. J Pediatr Adolesc Gynecol. 2006;19(4):271-5.

11. Harlow SD, Campbell OM. Menstrual dysfunction: a missed opportunity for improving reproductive health in developing countries. Reprod Health Matters. 2000;8(15):142-7.

12. Treloar SA, Heath AC, Martin NG. Genetic and environmental influences on premenstrual symptoms in an Australian twin sample. Psychol Med. 2002; 32(1):25-38

13. Gendall KA, Bulik CM, Joyce PR, McIntosh W, Carter FA. Menstrual cycle irregularity in bulimia nervosa. Associated factors and changes with treatment. J Psychosom Res. 2000;49(6):409-15.

14. Schneider MB, Fisher M, Friedman SB, Bijur PE, Toffler AP. Menstrual and premenstrual issues in female military cadets: a unique population with significant concerns. J Pediatr Adolesc Gynecol. 1999;12(4):195-201.

15. Angst J, Sellaro R, Merikangas KR, Endicott J. The epidemiology of perimenstrual psychological symptoms. Acta Psychiatr Scand. 2001; 104(2):110-6.

16. Schouten BC, Meeuwesen L. Cultural differences in medical communication: a review of the literature. Patient Educ Couns. 2006;64(1-3):21-34.

17. Hirai R, Frazier P, Syed M. Psychological and sociocultural adjustment of first-year international students: trajectories and predictors. J Couns Psychol. 2015;62(3):438-52

18. Labrague LJ, McEnroe-Petitte DM, Papathanasiou IV, Edet OB, Tsaras K, Leocadio MC, et al. Stress and coping strategies among nursing students: an international study. J Ment Health. 2018;27(5):402-8.

19. Chumlea WC, Schubert CM, Roche AF, Kulin HE, Lee PA, Himes JH, Sun SS. Age at menarche and racial comparisons in US girls. Pediatrics. 2003;111(1):110-3

20. Parent AS, Teilmann G, Juul A, Skakkebaek NE, Toppari J, Bourguignon JP. The timing of normal puberty and the age limits of sexual precocity: 
variations around the world, secular trends, and changes after migration. Endocr Rev. 2003;24(5):668-93.

21. Sadrzadeh S, Klip WA, Broekmans FJ, Schats R, Willemsen WN, Burger CW, Van Leeuwen FE, Lambalk CB. Group OP: birth weight and age at menarche in patients with polycystic ovary syndrome or diminished ovarian reserve, in a retrospective cohort. Hum Reprod. 2003;18(10): 2225-30.

22. Esimai $\mathrm{O}$, Esan GO. Awareness of menstrual abnormality amongst college students in urban area of ile-ife, Osun state, Nigeria. Indian J Community Med. 2010;35(1):63-6.

23. Gordley LB, Lemasters G, Simpson SR, Yiin JH. Menstrual disorders and occupational, stress, and racial factors among military personnel. J Occup Environ Med. 2000;42(9):871-81.

24. French L. Dysmenorrhea. Am Fam Physician. 2005;71(2):285-91.

25. Practice Committee of American Society for Reproductive. M: current evaluation of amenorrhea. Fertil Steril. 2008;90(5 Suppl):S219-25.

26. Apgar BS, Kaufman AH, George-Nwogu U, Kittendorf A. Treatment of menorrhagia. Am Fam Physician. 2007;75(12):1813-9.

27. Master-Hunter T, Heiman DL. Amenorrhea: evaluation and treatment. Am Fam Physician. 2006;73(8):1374-82.

28. Sweet MG, Schmidt-Dalton TA, Weiss PM, Madsen KP. Evaluation and management of abnormal uterine bleeding in premenopausal women. Am Fam Physician. 2012;85(1):35-43.

29. Care ACoAH. ACOG Committee opinion no. 349, November 2006: menstruation in girls and adolescents: using the menstrual cycle as a vital sign. Obstet Gynecol. 2006;108(5):1323-8.

30. Dennerstein L, Gotts G, Brown JB. Effects of age and non-hormonal contraception on menstrual cycle characteristics. Gynecol Endocrinol. 1997; 11(2):127-33.

31. Bagga D, Ashley JM, Geffrey SP, Wang HJ, Barnard RJ, Korenman S, Heber D. Effects of a very low fat, high fiber diet on serum hormones and menstrual function. Implications for breast cancer prevention. Cancer. 1995;76(12):2491-6.

32. Sternfeld B, Jacobs MK, Quesenberry CP Jr, Gold EB, Sowers M. Physical activity and menstrual cycle characteristics in two prospective cohorts. Am J Epidemiol. 2002;156(5):402-9.

33. Windham GC, Elkin EP, Swan SH, Waller KO, Fenster L. Cigarette smoking and effects on menstrual function. Obstet Gynecol. 1999:93(1):59-65.

34. Eskenazi B, Gold EB, Samuels SJ, Wight S, Lasley BL, Hammond SK, O'Neill Rasor M, Schenker MB. Prospective assessment of fecundability of female semiconductor workers. Am J Ind Med. 1995;28(6):817-31.

35. Harlow SD, Matanoski GM. The association between weight, physical activity, and stress and variation in the length of the menstrual cycle. Am J Epidemiol. 1991;133(1):38-49.

36. Pearlstein T, Yonkers KA, Fayyad R, Gillespie JA. Pretreatment pattern of symptom expression in premenstrual dysphoric disorder. J Affect Disord. 2005;85(3):275-82.

37. Janssen CA. A simple visual assessment technique to discriminate between menorrhagia and normal menstrual blood loss. Eur J Obstet Gynecol Reprod Biol. 1996;70(1):21-2.

38. Warner PE, Critchley HO, Lumsden MA, Campbell-Brown M, Douglas A, Murray GD. Menorrhagia I: measured blood loss, clinical features, and outcome in women with heavy periods: a survey with follow-up data. Am J Obstet Gynecol. 2004;190(5):1216-23.

39. Hallberg L, Hulthen L, Bengtsson C, Lapidus L, Lindstedt G. Iron balance in menstruating women. Eur J Clin Nutr. 1995;49(3):200-7.

40. Jensen JT, Lefebvre P, Laliberte F, Sarda SP, Law A, Pocoski J, Duh MS. Cost burden and treatment patterns associated with management of heavy menstrual bleeding. J Women's Health (Larchmt). 2012;21 (5):539-47.

41. El-Gilany AH, Badawi K, El-Fedawy S. Epidemiology of dysmenorrhoea among adolescent students in Mansoura, Egypt. East Mediterr Health J. 2005;11(1-2):155-63.

42. Parker MA, Sneddon AE, Arbon P. The menstrual disorder of teenagers (MDOT) study: determining typical menstrual patterns and menstrual disturbance in a large population-based study of Australian teenagers. BJOG. 2010;117(2):185-92.

43. Patel V, Tanksale V, Sahasrabhojanee M, Gupte S, Nevrekar P. The burden and determinants of dysmenorrhoea: a population-based survey of 2262 women in Goa, India. BJOG. 2006;113(4):453-63.

44. Cohen S, Kamarck T, Mermelstein R. A global measure of perceived stress. J Health Soc Behav. 1983;24(4):385-96.
45. Chrousos GP, Torpy DJ, Gold PW. Interactions between the hypothalamicpituitary-adrenal axis and the female reproductive system: clinical implications. Ann Intern Med. 1998;129(3):229-40.

46. Bullen BA, Skrinar GS, Beitins IZ, von Mering G, Turnbull BA, McArthur JW. Induction of menstrual disorders by strenuous exercise in untrained women. N Engl J Med. 1985;312(21):1349-53.

47. Demir SC, Kadayyfcy TO, Vardar MA, Atay Y. Dysfunctional uterine bleeding and other menstrual problems of secondary school students in Adana, Turkey. J Pediatr Adolesc Gynecol. 2000;13(4):171-5.

48. Chang PJ, Chen PC, Hsieh CJ, Chiu LT. Risk factors on the menstrual cycle of healthy Taiwanese college nursing students. Aust N Z J Obstet Gynaecol. 2009;49(6):689-94

49. Titilayo A, Agunbiade OM, Banjo O, Lawani A. Menstrual discomfort and its influence on daily academic activities and psychosocial relationship among undergraduate female students in Nigeria. Tanzan J Health Res. 2009;11(4):181-8.

50. Tavallaee M, Joffres MR, Corber SJ, Bayanzadeh M, Rad MM. The prevalence of menstrual pain and associated risk factors among Iranian women. J Obstet Gynaecol Res. 2011;37(5):442-51.

51. Mohebbi Dehnavi Z, Jafarnejad F, Sadeghi Goghary S. The effect of 8 weeks aerobic exercise on severity of physical symptoms of premenstrual syndrome: a clinical trial study. BMC Womens Health. 2018:18(1):80.

52. Feng GS, Chen JW, Yang XZ. Study on the status and quality of sleeprelated influencing factors in medical college students. Zhonghua Liu Xing Bing Xue Za Zhi. 2005;26(5):328-31.

53. Wyatt KM, Dimmock PW, Hayes-Gill B, Crowe J, O'Brien PM. Menstrual symptometrics: a simple computer-aided method to quantify menstrual cycle disorders. Fertil Steril. 2002;78(1):96-101.

\section{Ready to submit your research? Choose BMC and benefit from:}

- fast, convenient online submission

- thorough peer review by experienced researchers in your field

- rapid publication on acceptance

- support for research data, including large and complex data types

- gold Open Access which fosters wider collaboration and increased citations

- maximum visibility for your research: over $100 \mathrm{M}$ website views per year

At $\mathrm{BMC}$, research is always in progress.

Learn more biomedcentral.com/submissions 